\title{
Role Problems of Offenders and Correctional Workers*
}

\author{
EDWin J. Thomas \\ Professor, School of Social Work, and Department of Psychology. L'nitersity of \\ Michigan
}

A.B. (Sociology), 1951, M.S.W. (Psychiatric Social Hork). 1953. Wayne State University; Ph.D. (Social Psychology), 1956, University of Michigan

This paper analyzes selected problems of offenders and workcrs in correction as special cases of more general problems of role. The research findings, theory, and related concepts of social role are drawn upon for a better understanding of these specific problems and ways to alter them, and the emerging specialization of role theory is discussed. The role problems of offenders are considered in terms of nonlegitimate socialization, characteristics of the deviant position, role discontinuity, and role confict. The problems of correctional workers are set forth in terms of role discontinuities, role conflict and dissensus, role ambiguity, and pressure and strain. The identification of these various role prob. lems carries implications for their solutions. As one perspective and body of knowledge required to understand and control be. havior in real-life situations, role theory provides an emphasis upon the web of external social determinants and thereby helps to counterbalance a pervasive tendency to view personal difficultiles as individual psychological maladies independent of the social environment.

$\mathbf{T}$ HE PURPOSE OF THIS PAPER is to analyze selected problems of offenders and workers in correction as special cases of more general problems of role. I shall select problems for which the concepts of role theory have applicability and endeavor to indicate what is generic about these difficulties from the role perspective.

Recasting problems of correction in this way accomplishes more than a mere translation. The conceptualiza-

- Based on a paper presented at a conference of the Ohio Probation and Parole Association at the University of Toledo, March 26-27, 1965. tion of a specific, concrete problem as an instance of a more general phenomenon makes it possible to draw on what is known about the general phenomenon-research findings, theory, and related concepts-to understand the specific problem better. Practical implications for action on the specific problem are certainly among the by-products of this activity, but, as will be apparent, this mode of analysis tends to emphasize the general role difficulties that may require alteration rather than one or another of the many concrete, alternative actions that might be undertaken to change a general difficulty. 


\section{Role Theory and the Present Task}

Role theory is a relatively new field of study that is on the threshold of becoming a distinct specialization in the behavioral sciences. ${ }^{1}$ Role analysts examine patterned forms of complex real-life behavior, which includes the types and varieties of differentiated aggregates ( e.g., sex roles, age grades, kinship categories), social positions, specializations, and divisions of labor. Communication, learning and socialization, sanctioning and conformity, and interdependence are also among the processes examined both for individuals and for aggregates. This paper analyzes the positions of offenders and correctional workers, with emphasis upon the role problems associated with these positions.

From the viewpoint of role theory, human behavior results in large meas. ure from social prescriptions and from the behavior of others, and individual variations in performance, to the extent that they do occur, are expressed within the framework created by these factors. Thus, in this analysis, the role problems identified for offenders and correctional workers will highlight mainly the operation of the external, social determinants that generate and maintain such difficulties.

The rich and complex language of role theory serves to articulate complex, real behavior as well as, or better than, any other single, analogous vocabulary in the behavioral sciences. But a comprehensive battery of concepts required to describe and study

1 These general comments about the components of role theory are drawn from Edwin J. Thomas and Bruce J. Biddle, "The Nature and History of Role Theory." Role Theory: Concepts and Research, Bruce J. Biddle and Edwin J. Thomas, eds. (New York: Wiley, 1966), ch. I. complex real-life behavior does not yet exist and too many of the existing concepts are denotatively imprecise. The ideal of one complete set of clearly defined concepts with unequivocal referents still has to be attained in role theory. Only a few of the con. cepts of role will be employed in this analysis. Role and position are central among these, of course; the notions of role conflict, role discontinuity, role ambiguity, role pressure, and role strain are also among those used.

Role theory is also a body of knowledge-wide-ranging, diverse, and informative. But the knowledge resides in hundreds of different sources and is mainly uncollated and unorganized, for it has yet to be reviewed or evaluated. It is diffult, therefore, to do more than illustrate its scope and depth.

It should be mentioned that the phrase "role theory" is misleading. There are certainly hypotheses and theories about particular aspects of the subject, but there is no one granc "theory."

\section{Role Problems of Offenders}

\section{Nonlegitimate Socialization}

Even casual familiarity with offend. ers or with the sociology of deviance indicates that a significant number of offenders have been socialized to be deviant. For these offenders, the deviant act has been learned from other similar offenders. It is consistent with the norms of the deviant group, those norms being defined typically in opposition to those of legitimate society. The deviant group reinforces the deviance and punishes many behaviors considered desirable by legitimate society; the role models, such as peers, friends, or even parents either are exemplars of deviant behavior or are 
otherwise poor representatives of the role models sanctioned by the legitimate world. The career routes readily available to such individuals make it easier to remain in deviant positions than to enter and remain in nondeviant categories. In brief, social learning and role training have conspired to create a person for whom the commission of various deviant acts is normal, expected behavior.

As emphasized above, the simple fact of having been socialized nonlegitimately is itself a significant determinant of the commission of deviant acts. While it is this nonlegitimate socialization that looms large from the perspective of role theory, we should not ignore other conditions that may accompany nonlegitimate socialization and thereby contribute to the commission of deviant acts, or that may function independently of nonlegitimate socialization. Here I am thinking of the lack of opportunity and the tremendous emphasis in American society upon success and achievement, as well as of various personal difficulties that may predispose individuals to commit deviant acts.

\section{Characteristics of Deviant Position}

A position is a collectively recognized category of persons in which the individuals are differentiated from others on the basis of their common attributes, their common behavior, or the common reactions of others in society. ${ }^{2}$ The designations "delinquent," "criminal," "drug addict," "prostitute," and "alcoholic" are names for various deviant positions exemplifying these characteristics.

A deviant position is typically an established part of a continuous social

2 See Thomas and Biddle, "Basic Concepts for Classifying the Phenomena of Role," supra note 1 , ch. II. unit and, from the point of view of the individual, is a social given - some. thing he himself did not create. It is generally socially defined and external to any given individual. ${ }^{3}$ This is the first and most elemental way in which deviance may be construed as socially created.

But the fact that the deviant position is externally created and sustained does not distinguish it from many other positions, for there are few positions that the individual himself creates. The important implication, in this context, is that if the very existence of the category is in part due to its recognition by others and their common reactions to it, then it is conceivable, in principle, to change or even eliminate the position through modification of precisely these factors.

Consider this example of the alteration of a deviant position. A new specialized residence admitted only boy offenders between the ages of twelve and fifteen who were "disturbed," all of them "mess-ups" and past "failures." 4 There soon emerged the position designated as "ding," a "super mess-up," as it were. Individuals so identified typically "acted crazy," thus violating the rules of proper behavior held by staff members and causing the staff immense annoyance. Any boy who acted crazy in certain ways was called a "ding" by staff and boys alike; the staff treated "dings" differently by giving them much attention

3 For a related discussion of deviance, see Howard S. Becker, Outsiders (New York: Free Press, 1963). For a related discussion of this problem in the public school, see Robert D. Vinter and Rosemary C. Sarri, "Malperformance in the Public School: A Group Work Approach," Social Work, January 1965, pp. 3-14.

4 William Crain, "The Chronic 'Mess-Up' and His Changing Character," Federal Pro bation, June 1964, pp. 50-56. 
and surveillance and by placing them together in a special unit. "Nondings" reacted to "dings" with some contempt combined, apparently, with a peculiar, implicit admiration. Out of what appeared to be some desperation, the staff acted so as to eliminate most aspects of the "ding" position. Specifically, they eliminated the special unit for "dings" and stopped treating these boys as a separate category. They reacted to "ding-up" behavior as something any boy might engage in at least temporarily, at various times, rather than as an action that branded a boy as a type who fell into a category that was to be treated differently thereafter. Thus the problematic behavior of "dinging up" was reduced as were numerous, attending problems of behavioral management. Some "ding. up" behavior continued, as could be expected, but it presented fewer problems for the staff.

Another characteristic of the deviant position involves the conditions governing entrance into it. Membership in a deviant position, as in many other positions, is not entirely volitional. Most persons commit deviant acts at one time or another, but only relatively few are recognized as deviant position members becaues of this. Not all violators of the law are apprehended, processed by a sanctioning system, and thereby entered into a position called "offender," "delinquent," or "criminal." Furthermore, not all members of deviant categories have committed the acts presumably requisite to entering such categories. Rules are enforced by enforcers. As Becker has put it, someone has to "blow the whistle." In short, an individual who has committed a deviant act cannot become an offender without having been so defined by members of a rule-enforcing community.
This is the second way in which deviance is to be construed as a social phenomenon.

Rule enforcement not only is disproportionate to the deviant act but is selective and biased as well. Social class standing, ethnic group membership, neighborhood characteristics, and the circumstances under which an act was committed determine whether an individual will be apprehended and subjected to sanction. Most of these factors that differentially affect law enforcement are also socially regulated and external to the individual. This is the third sense in which deviance is to be understood as socially rather than as individually created.

The deprivation attending membership in a deviant position may take various forms for offenders: group exclusion, condemnation, stigma, restriction of freedom, fines, and incarceration. All of this is commonplace. Per haps less commonplace is the growing evidence that deprivation is likely to affect adversely a person's self-esteem and self-conception, 5 thereby decreasing the likelihood that individuals classified as deviant will act in nondeviant ways.

Still another characteristic of the deviant position is its centrality, which is the extent to which an individual's simultaneous membership in other positions is affected by the very

5 For instances of related evidence, see J. R. P. French, Jr., "The Social Environment and Mental Health," Journal of Social Issues October 1963, pp. 39-56; Ezra Stotland, Stan. ley Thorley, Edwin Thomas, Arthur R. Cohen, and Alvin Zander, "The Effects of Group Expectations and Self-Esteem upon Self Evaluation," Journal of Abnormal and Social Psychology, January 1957, pp. 55-63; Walter C. Reckless, Simon Dinitz, and Ellen Murray, "Self-Concept as an Insulator against Delinquency," American Sociological Review, December 1956, pp. 744-47; Vinter and Sarri, supra note 3, pp. 9-10. 
fact of having entered the deviant position in our society. In some cases, there is simply an enforced restriction of membership in other positions; for example, confinement of the offender removes him from associational, communal, occupational, and even possibly familial positions. Less extreme examples readily come to mind. Membership in a deviant position typically has the consequence of conspiring against engaging in legitimate activities that would ordinarily be associated with the positions lost because of this membership.

Positions have conditions of departure as well as conditions of entrance and maintenance, and deviant positions are no exception. The problem in departing from a deviant position is simply that leaving it is difficult. We are all familiar with how a criminal record may haunt and bedevil an offender long after he has been released from prison. A deviant reputation is difficult to change, as are the official records of various organizations in which deviant activities are regularly documented. The effect of membership in a deviant position is very much akin to a branding. An integral part of this branding effect is that others often generalize the deviant acts to realms of behavior to which the deviant acts are unrelated; thus the deviant person's honesty, responsibility, industriousness, competence, and intelligence may frequently be impugned.

All of the characteristics of deviant positions discussed above serve, in various ways, to foster the commission of the very acts to which the deviant position relates. As a consequence of being classified as a particular type of deviant an individual may come to view himself as deviant and then behave consistently with this deviant identity. Thus the very categorization of an individual as deviant is partly a "self-fulfilling prophesy" by those who place him in that category or react to him subsequently. ${ }^{6}$

\section{Role Discontinuity}

All movement from one position to another involves the possibility of role discontinuity. The behaviors expected of the member of any two positions may not be graded so that performance in one position serves as a stepping stone to performance in the next. The behaviors associated with one position may presuppose, for their performance, that the individual unlearn what he had mastered earlier in another position; sometimes what an individual has learned in one position may simply interfere with what is expected in another. ${ }^{7}$

There are many points of potential role discontinuity in the positional career of an offender. In his preoffender period, he is typically a member of positions in a family, a peer group, a community, and also possibly an occupation. Upon becoming designated as an offender, he may relinquish some of these positions, especially if incarceration results from the deviant act, at which point he most probably will be socialized into the inmate position, and this is typically a striking discontinuity, at least for most first offenders. If the institution is cus-

6 See Kai T. Erikson, "Notes on the Sociology of Deviance," The Other Side: Perspectives on Deviance, Howard S. Becker, ed. (New York: Free Press, 1964), pp. 9-23. For an elaboration of these problems for malper. formers in public school, see Vinter and Sarri, supra note 3, pp. 9.10.

7 The concept of role discontinuity was initially developed by Ruth Benedict in "Continuities and Discontinuities in Cultural Conditioning," Psychiatry, January 1938, Pp. 161 . 67. 
todial, the complex of behaviors associated with the concept of "prisonization" will usually accompany adaptation to the inmate position. And even if the institution is oriented toward treatment rather than custody, this too is a new position with its own set of particular expected behaviors. After his tenure as an offender, the individual must make the transition from the inmate position to the various social positions associated with life outside the institution. There may not be a clear-cut niche in the family into which he may move; he may lack skills to take a job; he may have been incarcerated so long as to have lost essential familiarity with life on the outside; and so on.

By anticipatory socialization ${ }^{8}-$ the prior acquisition and rehearsal of the behaviors expected in the position into which he is about to move-the individual, in part, prepares himself for positional movements, adopting new attitudes and rehearsing new behaviors. For inmates of correctional communities, ${ }^{9}$ anticipatory socialization appears in part as a "resocialization effect," and it is characterized by a gradual moving away from the orientations of the prisoner group toward those of the staff and the society at large as the end of the imprisonment period is approached. Such "resocialization" would appear to be adaptive, in part, for inmates about to resume positions in the legitimate world. But not all anticipations of inmates about to leave incarceration are necessarily adaptive. Workers in training schools for youthful offenders, for example,

8 This concept has been developed by Robert K. Merton, Social Theory and Social Structure, rev. ed. (New York: Free Press, 1957), pp. $265 \cdot 71$.

9 Stanley Wheeler, "Socialization in Correctional Communities," American Sociological Review, October 1960, pp. 697-712. have noted the increase in adjustmental difficulties of children about to leave the institution when they anticipate returning to difficult, unpleasant home environments. ${ }^{10}$

While anticipatory socialization may soften an impending positional transition, it is probably rarely sufficient in itself to insure continuity. Generally, more active efforts are required, especially in cases of relatively high discontinuity. Prerelease planning is a well-known example of these efforts. But it is probable that these services, even when well provided, do not often fully remove the role discontinuities attending the positional movements of most offenders. ${ }^{11}$

\section{Role Conflict}

Role conflict, one of the most common of role difficulties, occurs when role expectations are in opposition to each other so that the individual exposed to them cannot behave consistently with both at the same time.12 Role conflict may be common at many points in an offender's career. Outside an institution, the offender may be exposed to deviant norms from his peer group that are in opposition to

10 For example, see James $R$. Mackay and Alice H. Collins, "Leaving the Training School," Federal Probation, December 1959, pp. 38-43.

11 The subtlety and complexity of programs required to ease the transition between - very different positions is well illustrated in A. T. M. Wilson, E. L. Trist, and Adam Curle, "Transitional Communities and Social Reconnection: A Study of the Civil Resettlement of British Prisoners of War," Readings in Social Psychology, rev. ed., G. E. Swanson, T. M. Newcomb, and E. L. Hartley, eds. (New York: Holt, 1952), pp. 561-82.

12 Role conflict, as defined here, is but one form of polarized dissensus - namely, that which pertains to polarized prescriptions. For additional details, see Thomas and Bid. dle, supra note 2. 
these of his family or of representatives of society at large. In a correctional facility the inmate is typically exposed to conflict between the norms of the inmate culture and those of the staff. The most significant role conflict for offenders is obviously that between expectations to commit deviant acts as opposed to those not to commit such acts.

\section{Role Problems of Correctional Workers}

\section{Role Discontinuities}

The main cause of role discontinuities for correctional workers is the difference between their training and the demands made of them in their work. Many of them have not had training that fully prepares them for these demands. Workers entering the field without prior training in social work generally do not have sufficient knowledge of either social work or correctional practices to make a continuous transition into the job of worker. The worker just entering the field with a master's degree in social work generally -faces a somewhat different problem-namely, the lack of familiarity with the setting and its control practices.

There are also discontinuities in moving from the position of worker to that of supervisor or from supervisor to that of administrator. With relatively few exceptions, most of the required skills, knowledge, and attitudes differ for these various positions.

Role discontinuities are important because they engender role conflicts and these, in turn, are directly related to the role strain experienced by the person involved. ${ }^{13}$

13 For further details, see William J. Goode, "A Theory of Role Strain," American Sociological Review, August 1960, pp. 483-96.

\section{Role Conflict and Dissensus}

A few years ago, Hardman examined the job of the probation officerwhat he did and what his functions were. He observed that "if you should ask a hundred probation officers how they perceive their roles, you would be astonished at the diversity of opinion." $14 \mathrm{He}$ went on to discuss some of the common "roles" he had encountered in his informal inquiry, these being labeled as follows: "employment agent"; "vocational counselor"; "marital counselor"; "school counselor"; "psychoanalyst, junior grade"; "dream interpreter"; "street corner watcher"; "movie watcher"; "sports analyst"; "sheriff, deputy grade"; "father confessor"; and "moralist." He then proceeded to indicate what he thought were the three principal functions of the probation officer: (1) social consultation ("to help the offender comply with the order of the court"), (2) integrating services, and (3) expertness in the use of authority.

A subsequent issue of the journal printed reactions to Hardman's paper. ${ }^{13}$ These ranged from wholehearted support to outright condem. nation, with varying shades of opinion falling between. One officer observed:

Mr. Hardman has wrapped himself in a neat, narrow package of easy limits for the probation officer. Many of his con. cerns about the offender he refers to other agencies. He burlesques many of the roles needed to be played by social workers in the correctional field. If I were an offender, I most certainly would not want to report to a Mr. Hardman. . . . The offender needs a good, moral, knowledgeable friend to lean upon, one who will help him to help himself.

\footnotetext{
14 Dale G. Hardman, "The Function of the Probation Officer," Federal Probation, September 1960, p. 3.

15 Federal Probation, March 1961, pp. 62.
} 65. 
Another writer said, in objection:

The question is are we caseworkers or aren't we?

Still another writer observed:

I could not help but have the feeling that he had geared this article toward the untrained and nonprofessional probation officer.

The opinions depicted above suggest widepread disagreement concerning what the role of the probation officer is. Such nonpolarized disagreement concerning role behavior is generally called "role dissensus." A more searching scrutiny of the problem reveals. however, that these different activities are polarized around the two different goals of control and assistance, defined in Glaser's inquiry into types of parole supervision officers. ${ }^{16}$

The three major types of activities relating to control were surveillance, restriction, and punishment; the four major components of assistance were material aid, referral, counseling, and mediation. A questionnaire containing 175 questions to probe these different matters was administered by Glaser and his associates to $486 \mathrm{fed}$ eral probation officers, 96 per cent of the total number in service in 1962. On the basis of the responses to these questions, two independent scales were developed, one for assistance and one for control. Every officer was then classified as falling into one of four types of parole supervision officer. These types were (1) the "welfare officer" (high emphasis on assistance and low emphasis on control), (2) the "paternal officer" (high emphasis on both assistance and control), (3) the "punitive officer" (low emphasis on assistance and high emphasis on

16 Daniel Glaser, The Effectiveness of a Prison and Parole System (New York: BobbsMerrill, 1964), pp. 423.42. control) and (4) the "passive officer" (low emphasis on both assistance and control). These types are generally comprehensive of those reported in the literature, according to Glaser. For example, the "punitive officer," "welfare worker," and "protective agent" of Ohlin, Piven, and Pappenfort $^{17}$ correspond to the similarly named types developed by Glaser. Glaser's four types are to some extent extremes, however, and, as he himself recognizes and as his data revealed, the majority of the officers tended to fall some place in the middle range on both assistance and control.

The general goals and functions of assistance versus control may be the focal points for role conflict for many correctional workers. The conflict may take many forms. Thus a worker ex. pected to achieve a high degree of both control and assistance may, because these are different, independent activities, find it difficult to perform both sufficiently well. Or, a worker disposed by virtue of training or personal propensity to provide a high degree of assistance may be located in a setting in which a high degree of control and only a moderate degree of assistance are expected; or the reverse situation may obtain.

Role conflict and dissensus result in a number of performance problems and personal difficulties. It is axiomatic that in the face of opposing behavioral expectations, the individual cannot simultaneously conform to all at the same time or fulfill them well. Thus, there will be nonconformity at least to some of the behavioral expectations. Another problem is performance variability. The individual is

17 Lloyd E. Ohlin, Hermin Piven, and Donnell M. Pappenfort, "Major Dilemmas of the Social Worker in Probation and Parole," NPPA Jotırnal, July 1956, PP. 211-25. 
constrained to attempt to conform at least to some extent to all of the disagreeing behavioral expectations, despite the fact that it is impossible to meet all of them at once. In his efforts to serve many masters, he must necessarily perform differently and therefore his overall performance is likely to be highly variable. A related problem is that of performance inadequacy. If the adequacy of an individual's performance is determined, in part, by the extent to which he meets behavioral expectations, then, clearly, the existence of opposing expectations means that, at least sometimes, he will be performing inadequately in terms of one or another of these expectations. Finally, he is likely to experience considerable role strain. This may be manifested as ambivalence, indecision, anxiety, and stress in general. The conflict and dissensus, resulting from the assignment of disparate functions to be performed by members of a single position, are well illustrated by the difficulty in fulfilling the functions of assistance and control, for each relates to a different objective and consists of relatively independent activities.

A related aspect of role conflict, and one that almost always attends it, is the conflict between the goals of an organization. Grusky's observations on this topic are pertinent:

The official goals of an organization determine in large part the types of role expectations associated with the positions that make up the goal structure. If an organization is assigned a new major goal, and if this goal is in conflict with what formerly was the only primary goal of the system, then we would expect that conflict between the goals would create new stresses for many members of the organization. These two or more sets of conflicting role expectations, defined by the organization as legitimate by the fact that they are derived from the official goal, create role conflict.

The increasing emphasis on quasi-envi. ronmental, rehabilitation or "milieu" treatment programs in organizations such as prisons and mental hospitals, which formerly have had primarily custodial goals, presents a situation containing the necessary ingredients for such role conflict. ${ }^{18}$

Grusky's study of the staff members of a small midwestern prison camp found support for his hypothesis that role conflict among prison camp officials stemmed directly from the confict between the organization's formal goals of custody and treatment.

Another source of role conflict may be the disagreement between the role expectations of a profession and those of the organization and bureaucracy in which members of the profession work. The social worker in a correctional setting may experience the pangs of this conflict. The professional organization in social work as well as the professional schools of social work are more likely to emphasize activities of assistance, whereas many of the correctional settings emphasize the control theme. ${ }^{10}$

Underlying many of the disagreements concerning the proper functions of the correctional worker are broad societal disagreements. There is general disagreement concerning the amount and type of punishment that should attend crime and deviance, and little agreement concerning the amount and type of rehabilitation for offenders. These societal disagreements are bound to be reflected in the

18 Oscar Grusky, "Role Conflict in Organization: A Study of Prison Camp Officials," Administrative Science Quarterly, March 1959, pp. 452-53.

19 Ohlin et al., supra note 17. 
various structures and functions in the field of correction. As I was perusing Federal Probation one day, this point was markedly impressed upon me by the titles of the articles. Consider these titles that I found in but one volume of this journal, published in 1961: "What's So Good about Parole?"; "The Delinquent Child: Whose Responsibility?"; "Delinquency and Juvenile Courts: Confusion and Diversity"; "Punishment versus Treatment?"; "What Price Punishment?"; "The 'Authority Problem' Revisited."

\section{Role Ambiguity}

Role ambiguity is the lack of clarity in the behavioral expectations associated with a position. ${ }^{20}$ I am talking about the unclarity in the expectations themselves, not the personal confusion that it often engenders. An expectation may be incompletely specified in not identifying the persons to whom it applies, or in not specifying the time, place, or other conditions under which the behavior is to be engaged in. ${ }^{21}$ The role expectations defining the behavior of workers are often articulated in writing-in manuals of operation, codes of ethics, and the practice principles of the field and profession-and they are expressed informally in the verbalizations of supervisors, colleagues, clients, and family members. Written role expectations tend more often to be complete

20 For a detailed report on role ambiguity, see Robert L. Kahn, Donald M. Wolfe, Rob. ert P. Quinn, J. Diedrick Snoek, in collaboration with Robert A. Rosenthal, Organizational Stress: Studies in Role Conflict and Ambiguity (New York, Wiley, 1964), Pp. 11 34, 72.97.

21 There are many features of prescriptive phemonena that may not be completely specified, and these are but a few. than nonwritten ones, although this is not always the case. ${ }^{22}$ For instance, consider the ambiguity in the principles of practice in social work reflected, in part, in Shireman's comments on casework in probation and parole:

We do treat in corrections, and we often treat successfully. But in all honesty we are forced to admit that much of our work rests upon no organized treatment theory at all, or upon the assumptions still only partially tested, or, sometimes, upon little more than pious hope. We do not yet have available to us in our work a systematic body of theory and knowledge which can be tested, built upon, added to, and taught. The further development of treatment theory in corrections is a major responsibility of the present as well as future generations of practitioners and scholars. [Italics added.] ${ }^{23}$

The principles of practice of casework and of social work in general are often nonspecific regarding means; that is, they do not indicate the details of "what," "how," "where," and "when" with sufficient completeness and specificity. Generally they do not indicate, in specific concrete detail, who needs what treatment and under what conditions so that one may know exactly what must be done. Again, this is not to say that casework help is not provided and that people are not aided by it, but rather that the principles of practice which presumably guide the casework services are often

22 The concepts of role ambiguity, role expectation, and many others used here have been programmed in an elementary primer: Edwin J. Thomas and Ronald A. Feldman, with the assistance of Jane Kamm, "Concepts of Role Theory," Behavioral Science for Social Workers, Edwin J. Thomas, ed. (New York: Free Press, in press), sec. 2.

23 Charles H. Shireman, "Casework in Probation and Parole: Some Considerations in Diagnosis and Treatment," Federal Proba. tion, June 1963, p. 51. 
ambiguous as role expectations for worker behavior.

\section{Pressure and Strain}

The metaphors "pressure" and "strain" are terms for two sides of an important coin in role theory. Pressure pertains to all those factors relating to role which singly or in combination are sources of potential diffculty for the individual. The discontinuities, conflicts, and disagreements and ambiguities of role already discussed are among the factors that define pressure. Strain, in contrast, has been defined by Goode as "the felt difficulty in fulfilling role obligations." 24 Strong and enduring pressure results, of course, in strain.

In addition to the role discontinuity, role conflict, and role ambiguity mentioned earlier, at least one other factor contributes to role pressure for the correctional worker-heavy workloads and the need to meet deadlines. Demands to perform a great deal of work in a relatively short period of time are almost endemic in many agencies and institutions.

While it is apparent that role strain is a result of and roughly proportionate to the magnitude of role pressure, the diverse ways in which it may be manifested are sometimes overlooked. In addition to the anxiety, stress, and indecision mentioned before, role strain may be manifested also as performance inefficiency, low morale, absenteeism, and employee turnover.

\section{Postscript}

One of the virtues of a role-theoretical analysis of any problem is that the solution to the difficulty is implied by identifying the general problematic

24Goode, supra note 13, p. 483. case. Thus, identifying a set of specific problems as being related to the discontinuity of role training makes it clear that at least some of the specific difficulties may be ameliorated by providing more continuous role training; by identifying an instance of role conflict, we show how that specific diffculty may be handled by reducing or eliminating the role conflict; by identifying a problem as involving role ambiguity, we indicate the appropriateness of achieving greater expectational clarity. In general, a role analysis of life problems singles out particular features of the external, social environment that give rise to given difficulties and, in so doing, suggests various courses of action that would not necessarily be apparent otherwise.

Another virtue of a role theoretical analysis is that it helps to counterbalance a pervasive tendency, particularly dominant in the helping professions, to view deviance as mainly a matter of individual, psychological dynamics and to give insufficient weight to the social and environmental determinants that enter so significantly into shaping human behavior. It is not the intent of role theory to displace purely psychological understanding. Rather, its contribution is no different from that of any other distinct body of knowledge about human behavior; namely, it orders phenomena according to its concepts, specifies antecedents and consequences when these are known, and, when used in practice, helps give proper weight to the numerous variables that typically determine behavior. Role theory is simply one among many perspectives and bodies of knowledge required to understand and control behavior. 